\title{
Enhancing Cobalt Dispersion in Supported Fischer-Tropsch Catalysts Via Controlled Decomposition of Cobalt Precursors
}

\author{
Andrei Y. Khodakov* \\ Unité de Catalyse et de Chimie du Solide - UMR 8181 CNRS, \\ Université des Sciences et Technologies de Lille, Bat C3, Cité scientifique, 59655 Villeneuve d'Ascq, France.
}

(Received on 1 July, 2008)

\begin{abstract}
Fischer-Tropsch synthesis is a part of Gas-to Liquids (GTL), Biomass-to-Liquids (BTL) and Coal to Liquids (CTL) technologies, which produce alternatives clean fuels from natural gas, biomass and coal. The catalytic performance of cobalt catalysts in Fischer-Tropsch synthesis strongly depends on the size of cobalt particles in nanoscale range $(6-30 \mathrm{~nm})$. Cobalt catalysts are usually prepared via incipient wetness impregnation using cobalt salts (cobalt precursors). Catalyst preparation involves several important steps. The paper shows that decomposition of cobalt precursors is often a crucial step in the catalyst design; slower rate of decomposition of cobalt precursors favors smaller size of cobalt particles, higher cobalt dispersion and enhances catalytic performance in Fischer-Tropsch synthesis.
\end{abstract}

Keywords: Fischer-Tropsch synthesis, cobalt, nanoparticles, clean fuels, catalyst design

\section{INTRODUCTION}

Fischer-Tropsch (FT) synthesis is a catalytic reaction [1-4] which converts mixtures of hydrogen and carbon monoxide (also called syngas) into liquid hydrocarbons and water:

$$
\begin{aligned}
& n \mathrm{CO}+(2 n+1) \mathrm{H}_{2} \rightarrow \mathrm{C}_{n} \mathrm{H}_{2 n+2}+n \mathrm{H}_{2} \mathrm{O} \\
& n \mathrm{CO}+2 n \mathrm{H}_{2} \rightarrow \mathrm{C}_{n} \mathrm{H}_{2 n}+n \mathrm{H}_{2} \mathrm{O}
\end{aligned}
$$

FT synthesis is an integral part of Gas-to Liquids (GTL), Biomass-to-Liquids (BTL) and Coal to Liquids (CTL) technologies [5]. In these technologies the syngas is generated respectively from natural gas, biomass and coal. Then the syngas reacts on cobalt or iron catalysts to yield a wide range of gaseous, liquid and solid hydrocarbons. Several industrial projects involving FT synthesis have been realized recently (Bitulu in Malasia, Oryx in Qatar) or are currently under construction (Pearl in Qatar, Escravos in Nigeria). The world consumption of crude oil in 2015 can be estimated as 20 millions barrels per day. If all GTL projects would have been realized by that time, the total GTL capacity might reach about 600000 bpd that only $3 \%$ of total crude oil consumption.

Because of higher stability, higher per single pass conversion (up to 60-70\%), higher productivity, smaller negative effect of water on conversion, higher resistance to attrition in slurry bubble column reactors, cobalt supported catalysts $[2,6,7]$ embody the optimal choice for synthesis of middle distillates and waxes. In the cobalt catalysts, the reaction proceeds on metal nanoparticles of 6-30 nm diameters [2, 8-10] Cobalt particles smaller than $6 \mathrm{~nm}$ usually exhibit poor catalytic performance in FT synthesis [11-13].

Iglesia $[8,10,14]$ et al have shown that FT reaction rate strongly depends on the number of cobalt metal surface sites. Higher density of cobalt metal surface sites usually results in higher catalytic activity. The number of metal sites in cobalt catalysts is strongly affected by metal nanoparticle size, cobalt reducibility and cobalt metal nanoparticle stability. Thus, the control of cobalt nanoparticle size, structure and

${ }^{*}$ Electronic address: andrei.khodakov@univ-lillel.fr proprieties appears to be vital in the design of efficient FT catalysts. Preparation of cobalt supported FT catalysts usually involves several important stages [2]: (i) modification and stabilization of catalyst support, (ii) deposition of cobalt and promoters on the support, (iii) decomposition of cobalt precursor and catalyst calcination, (iv) reducing pretreatments and catalyst passivation, (v) catalyst activation during the reactor start-up and on-stream during FT reaction...

While the structure of the final cobalt FT catalysts is a result of the whole preparation procedure, decomposition of cobalt precursor seems to be an essential step in the catalyst design which often determines the overall catalytic performance. The present paper focuses on the role of controlled decomposition of cobalt precursors in attaining optimal cobalt particle size and enhancing catalytic performance in FT synthesis. In this paper we present an overview of the data obtained for the catalysts prepared using incipient wetness impregnation.

\section{STRUCTURE OF COBALT SPECIES IN IMPREGNATED CATALYSTS}

In the incipient impregnation method of catalyst preparation, a solution of cobalt salt, typically cobalt nitrate is contacted with a dry porous support. After being contacted, the solution is absorbed by the capillary forces inside the pores of the support. The incipient wetness occurs when all pores of the support are filled with the liquid and there is no excess moisture, over and above the liquid required to fill the pores. Our previous works $[15,16]$ have shown that cobalt deposition on silica or alumina using aqueous incipient wetness impregnation with cobalt nitrate results in formation of mononuclear cobalt complexes. Figure 1 displays data obtained by Xray absorption spectroscopy for impregnated and dried cobalt alumina and silica supported catalysts. The XANES spectra and EXAFS Fourier transform moduli of the impregnated and dried catalysts are rather similar to those of cobalt nitrate. Thus, similarly to aqueous solution of cobalt nitrate, cobalt has octahedral coordination in the complexes deposited on silica or alumina surface via impregnation.

Cobalt repartition in silica supported catalyst during impregnation at different $\mathrm{pH}$ was characterized by XPS [15] 

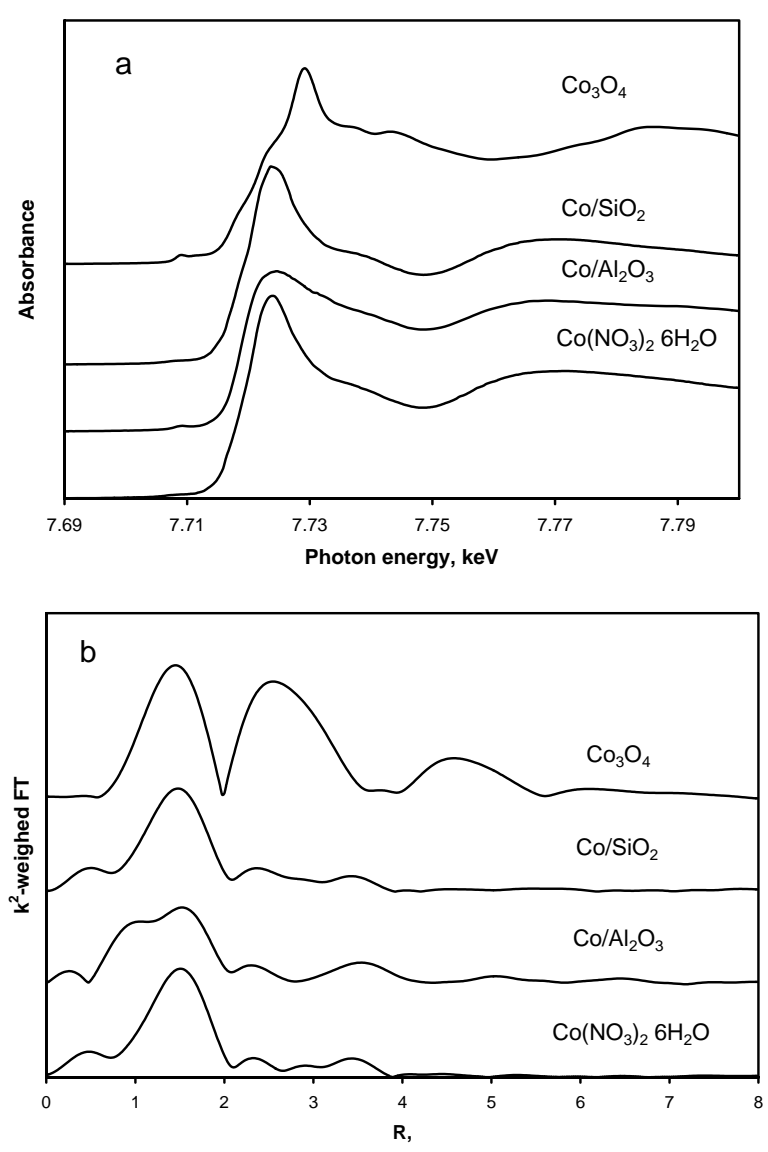

FIG. 1: XANES spectra (a) and EXAFS Fourier transform moduli (b) of cobalt nitrate, impregnated and dried cobalt alumina and cobalt silica supported catalysts (10\% wt. Co) and $\mathrm{Co}_{3} \mathrm{O}_{4}$.

The XPS spectra revealed the presence of $\mathrm{Co}^{2+}$ ions on the surface of impregnated and dried catalysts. The $I_{C o} / I_{S i}$ ratio of the XPS intensities provides information about repartition of cobalt ions on silica surface after drying. Higher $I_{C o} / I_{S i}$ ratios are characteristic of higher cobalt dispersion in the dried cobalt catalysts, while lower $I_{C o} / I_{S i}$ ratio indicates formation of cobalt agglomerates and lower cobalt dispersion $[2,17,18]$. Figure 2 displays the relation between the $I_{C o} / I_{S i}$ ratio and $\mathrm{pH}$ of the impregnating solutions. The observed increase in cobalt dispersion (higher $I_{C o} / I_{S i}$ ratio) with $\mathrm{pH}$ is attributed to different interaction with $\mathrm{Co}^{2+}$ ions and silica surface. The point of zero charge (PZC) of silica is situated at $\mathrm{pH}=3$ [19]. At $\mathrm{pH}$ higher than the $\mathrm{PZC}$, silica surface is negatively charged and there is some attraction between cobalt ions and surface; higher $I_{C o} / I_{S i}$ ratios are observed.

XPS shows that repartition of cobalt ions on the surface is getting more uniform with increase in $\mathrm{pH}$ value. At $\mathrm{pH}$ low than silica PZC, the surface is charged positively and $\mathrm{Co}^{2+}$ ions are repulsed from the silica surface. This results in nonuniform cobalt repartition and lower cobalt dispersion. This explains why cobalt dispersion in the impregnated and dried cobalt catalysts is largely affected by $\mathrm{pH}$ of the impregnating solution. Our previous studies have shown [15] that the presence of small amounts of ions of promoting noble metals and sucrose did not much affect the repartition of cobalt in impregnated and dried samples. It can be suggested that

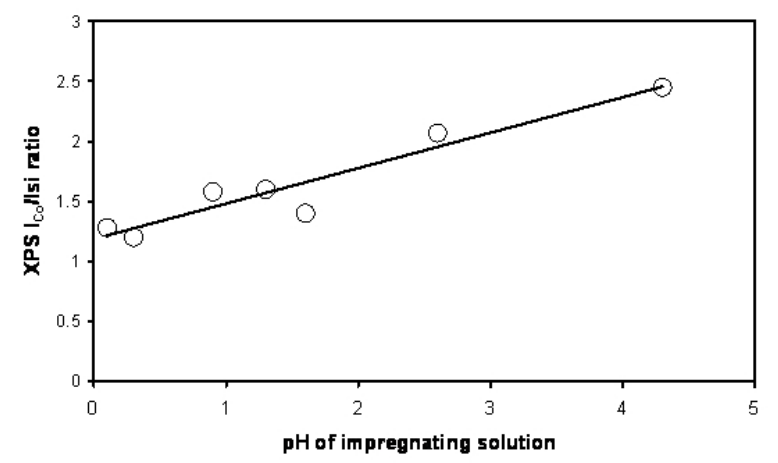

FIG. 2: XPS $I_{C o} / I_{S i}$ ratio in the impregnated and dried cobalt silica supported catalysts versus $\mathrm{pH}$ of the impregnating solution. Reprinted from [15] with permission from Elsevier.

in impregnated and dried catalysts, cobalt ions are principally linked to the support surface via electrostatic force. The repartition of cobalt in the impregnated and dried catalysts seems to be very unstable and could significantly evolve during further catalyst preparation steps.

\section{DECOMPOSITION OF COBALT PRECURSOR, A KEY TO BETTER COBALT DISPERSION}

Decomposition of supported cobalt nitrate complexes is typically a next step (after support stabilization, impregnation and drying) in the design of cobalt catalysts. Decomposition of cobalt precursor usually results in formation of cobalt oxide species which can be converted to the active cobalt metal phases via reduction with hydrogen. Decomposition of cobalt precursor could also yield barely reducible cobalt support mixed compounds which do not have active sites for FT synthesis.

Below we discuss the parameters of cobalt precursor decomposition which are susceptible to affect the structure of final catalysts and catalytic performance. Analysis of the available literature suggests that decomposition of cobalt precursor at milder conditions generally leads to higher cobalt dispersion. The suggestion about positive effect of slower decomposition of cobalt precursor on cobalt dispersion and catalytic performance is consistent with the earlier data of Van de Loosdrecht [20] et al who observed the beneficial effect of slower temperature ramping rate and higher space velocity during calcination on cobalt dispersion and number of active sites. De Jong $[21,22]$ et al used NO/He mixture to decompose metal nitrate in cobalt and nickel supported catalysts. It was shown that the presence of NO slowed down the rate of cobalt nitrate decomposition and enhanced cobalt dispersion. Borg [23] et al showed that lower calcination temperatures and efficient removal of the precursor decomposition products $\left(\mathrm{NO}, \mathrm{NO}_{2}, \mathrm{H}_{2} \mathrm{O}\right)$ enhance cobalt dispersion. Higher flow rate resulted in $30 \%$ higher FT activity per gram of catalyst.

The rate of decomposition of cobalt precursors could be possibly dependent on the following factors: temperature of decomposition, space gas velocity during decomposition, extermicitiy of cobalt precursor decomposition, catalyst sup- 


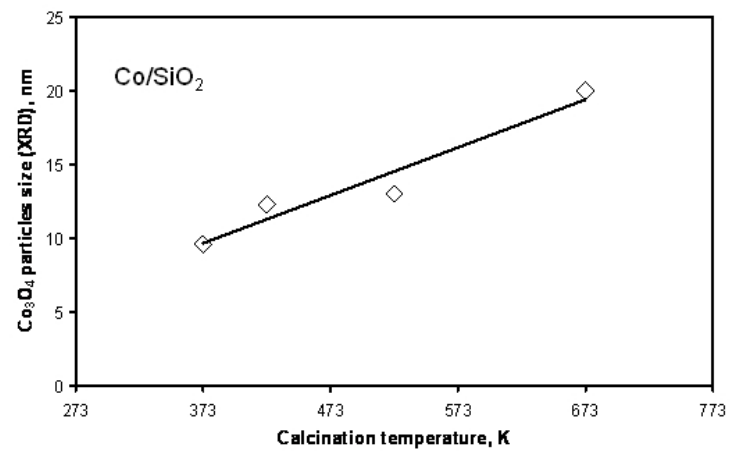

FIG. 3: Influence of calcination temperature on the size of cobalt oxide particles in silica supported catalysts.

port and catalyst promotion, use of unconventional techniques such as glow discharge plasma method...

Our previous reports $[24,25]$ have shown that decomposition of cobalt precursors at lower temperatures resulted in slower decomposition of cobalt nitrate and leads to smaller cobalt particles. Figure 3 shows the sizes of $\mathrm{Co}_{3} \mathrm{O}_{4}$ crystallites as a function of the temperature of cobalt nitrate decomposition. Smaller cobalt particles and respectively higher cobalt dispersion were observed when cobalt nitrate was decomposed at lower temperatures. Low catalyst calcination temperature also hinders sintering of cobalt oxide particles.

Exothermicity of decomposition of cobalt precursor is another important parameter which affects the genesis of small cobalt nanoparticles. Significant exothermic effect leads to uncontrolled high rate of decomposition of cobalt precursors and could favor formation of cobalt-support mixed compounds (such as cobalt silicate). Cobalt support mixed compounds do not produce active phases for FT synthesis. In previous report [25] a series of cobalt silica supported catalysts was prepared using impregnation with cobalt acetate. The decomposition of cobalt acetate in these catalysts was studied using differential calorimetry combined with thermogravimetric analysis. Decomposition of cobalt acetate in air resulted in a weight loss which was accompanied by a significant exothermic effect (Figure 4). Higher concentration of $\alpha$-orthorhombic cobalt silicate was detected in the catalysts prepared via rapid and highly exothermic decomposition of cobalt acetate. In agreement with these results, Mochizuki [26] et al have shown that rapid temperature ramp (above 1.0 $\mathrm{K} \mathrm{min}^{-1}$ ) during catalyst calcinations favors formation of irreducible $\alpha-\mathrm{Co}_{2} \mathrm{SiO}_{4}$-like species when cobalt silica supported catalysts are prepared with addition of -1,2-diaminocyclohexane-N,N,N',N'-tetraacetic acid. The catalysts had poor activity in FT synthesis. It has been also shown that the concentration of cobalt silicate can be reduced by conducting decomposition of the organic compounds more slowly.

Decomposition of cobalt precursor is also affected by the catalyst support. The influence of the support on cobalt precursor decomposition can involve several phenomena. First, the catalyst support can affect the rate of cobalt oxide nucleation and growth during cobalt precursor decomposition. Secondly, cobalt oxide produced during decomposition of cobalt precursor can react with the support yielding cobalt-

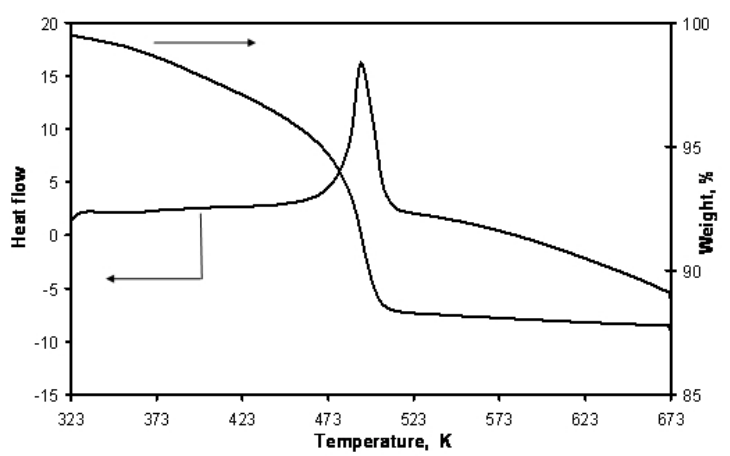

FIG. 4: DSC-TGA curves of silica impregnated with cobalt acetate. Temperature ramp $1 \mathrm{~K} / \mathrm{min}$. Reprinted from [24] with permission from Elsevier.

support mixed compounds [2]. In addition, Puskas [27] et al suggested that the catalyst structure could be affected by migration of $\mathrm{SiO}_{2}$ in cobalt silica supported catalysts during cobalt nitrate decomposition and thermal pretreatments.

The interaction between cobalt oxide and support is particularly pronounced with cobalt alumina supported catalysts. A series of cobalt alumina supported catalysts was prepared using decomposition of cobalt nitrate at different temperatures [16]. The size of $\mathrm{Co}_{3} \mathrm{O}_{4}$ crystallites in these catalysts measured using XRD was almost identical $\left(d_{C o 3 O 4}=9-10 \mathrm{~nm}\right)$. It is known that trivalent cobalt and aluminum have rather similar Pauling's ionic radii $\left(0.063 \mathrm{~nm}\right.$ for $\mathrm{Co}^{3+}$ and $0.054 \mathrm{~nm}$ for $\left.\mathrm{Al}^{3+}\right) . \mathrm{Co}^{3+}$ of $\mathrm{Co}_{3} \mathrm{O}_{4}$ can be gradually replaced [28] by $\mathrm{Al}^{3+}$ to produce the series of $\mathrm{Co}_{3-} \mathrm{Al}_{5} \mathrm{O}_{4}(0<\mathrm{s}<2)$ spinels. These series include $[29,30] \mathrm{CoAl}_{2} \mathrm{O}_{4}, \mathrm{Co}_{2} \mathrm{AlO}_{4}$, and $\mathrm{Co}_{3} \mathrm{O}_{4}$, etc. The interaction between $\mathrm{Co}_{3} \mathrm{O}_{4}$ and alumina could result in partial substitution of $\mathrm{Co}^{3+}$ ions in $\mathrm{Co}_{3} \mathrm{O}_{4}$ spinel by $\mathrm{Al}^{3+}$ ions and thus, would hinder the reduction of cobalt species. Figure 5 shows the temperature-programmed reduction profiles obtained for a series of cobalt alumina supported catalysts which were calcined at different temperatures. As expected, higher catalyst calcination temperature and consequently incorporation of $\mathrm{Al}^{3+}$ ion in $\mathrm{Co}_{3} \mathrm{O}_{4}$ crystallites resulted in higher temperatures of cobalt reduction.

Decomposition of cobalt precursor can be affected by the presence of promoters. It was found [25] that the presence of ruthenium nitrosyl nitrate in cobalt silica supported catalyst prepared from cobalt acetate influenced the kinetics of cobalt precursor decomposition. It was shown that cobalt acetate could be decomposed at slightly lower temperatures in the cobalt catalysts promoted with ruthenium than in monometallic cobalt counterparts. In addition, the presence of promotes affects crystallization of cobalt oxide species. Decomposition of cobalt nitrate in the presence of noble metals leads to smaller crystallites of cobalt oxide in silica supported catalysts than those obtained in unpromoted counterparts [15, 31]. One of the reasons responsible for higher cobalt dispersion in the catalysts promoted with noble metals could be related to a higher concentration of cobalt oxide nucleation and crystallization sites. Crystallization of cobalt oxide can occur on the sites associated with the noble metal promoters. Higher concentration of crystallization sites at the similar cobalt con- 


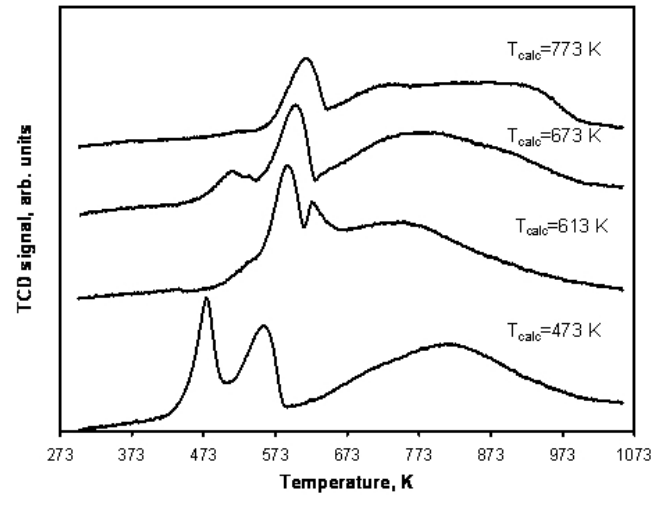

FIG. 5: TPR profiles of monometallic cobalt alumina supported catalysts calcined at different temperatures $\left(5 \% \mathrm{H}_{2} / \mathrm{Ar}\right.$ mixture, ramping rate $3 \mathrm{~K} / \mathrm{min}$ ). Reprinted from [16] with permission from Elsevier.

tent would result in larger number of cobalt particles and consequently higher cobalt dispersion in the catalysts. Higher cobalt dispersion in silica supported catalysts promoted with noble metals was one of the reasons responsible of their higher catalytic activity in FT synthesis.

Cobalt precursor in supported FT catalysts could be also decomposed using glow discharge (luminous) plasma. The glow discharge is obtained by applying a potential difference between two electrodes placed in gas. The glow discharge plasma has been used previously [32-35] for preparation of several active metal supported catalysts. Our recent report [36] has shown that a more gentle decomposition of cobalt nitrate in the glow discharge which proceeds at temperatures much lower than a conventional calcination, results in the enhancement of cobalt dispersion. It has been shown that decomposition of cobalt nitrate in alumina supported catalysts using nitrogen and hydrogen glow discharge plasma results in very small cobalt oxide particles. The reduction of these particles produces small cobalt metal particles. Figure 6 displays a dependence of magnetization on the magnetic field (field dependence curve) measured for cobalt alumina supported catalyst reduced at $673 \mathrm{~K}$ in hydrogen which was prepared using glow discharge plasma. The observed absence of hysteresis loop is characteristic of cobalt metal superparamagnetic particles which size is smaller than $7 \mathrm{~nm}$ at ambient conditions [37]. Cobalt catalysts which contained small superparamagnetic cobalt metal particles, exhibited higher activity in FT synthesis than their counterparts prepared using conventional calcinations [36].

\section{CONCLUSION}

Decomposition of cobalt precursors appears to be a key step in preparation of cobalt supported catalysts for FT syn- thesis. It is commonly observed that decomposition of cobalt precursors at milder conditions leads to smaller sizes of cobalt particles and enhances catalytic performance in FT synthesis.

Cobalt precursors in the supported catalysts are usually decomposed by calcination in a flow of air. High space velocity,

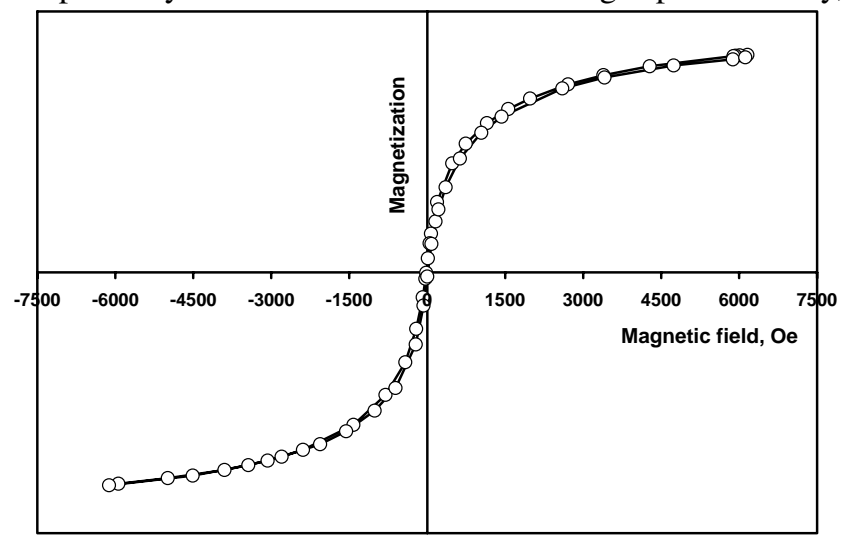

FIG. 6: Field dependence of the plasma assisted monometallic cobalt catalyst reduced in hydrogen showing the presence of small cobalt superparamagnetic particles $(\mathrm{d}<7 \mathrm{~nm})$.

slower temperature ramp, lower temperature usually results in smaller cobalt particle size and reduces the fraction of hardly reducible cobalt-support mixed compounds. High temperature calcination of catalysts obtained via low temperature decomposition of cobalt precursors should be avoided since it could lead to particle sintering and formation of cobalt support mixed compounds. Decomposition of cobalt precursors seems to be also affected by nature of support and presence of catalyst promoters. Cobalt precursors which decompose with release of significant amounts of heat, i.e. cobalt acetate, produce significant amounts of barely reducible cobalt-support mixed compounds. Gentle decomposition of cobalt precursor in glow discharge plasma seems to be a promising method to enhance cobalt dispersion.

\section{Acknowledgements}

The author is grateful to A. Griboval-Constant, P. Fongarland, W. Chu, M. Bremaud, J. Hong, J.-S. Girardon, S. Pietrzyk and E. Payen for collaboration and fruitful discussions. The collaboration with P.A. Chernavskii in the area of catalyst characterization using magnetic method is particularly appreciated. The author thanks S. Nikitenko for help with X-ray absorption measurements. The European Synchrotron Radiation Facility (ESRF) is acknowledged for the use of synchrotron beam time.
[1] R.B. Anderson, The Fischer-Tropsch Synthesis, Academic Press, New York, 1984.
[2] A.Y. Khodakov, W. Chu, P. Fongarland, P. Chem. Rev. 107, 1692(2007). 
[3] M.E. Dry, Catal. Today 71, 227(2002).

[4] H. Schulz, Appl. Catal. A 186, 3(1999).

[5] S. Fedou, E. Caprani, D. Douziech and S. Boucher, Petroleum Technology Quarterly 13, 87(2008).

[6] B. Jager, Stud. Surf. Sci. Catal. 119, 25(1998).

[7] B. Jager and R. Espinoza, Catal. Today 23, 17(1995).

[8] S.L. Soled, E. Iglesia, R.A. Fiato, J.E. Baumgartner, H. Vroman, S. Miseo, Top. Catal. 26, 101(2003).

[9] E. Iglesia, E. Appl. Catal. A 161, 59(1997).

[10] E. Iglesia, S.C. Reyes, R.J. Madon and S.L.Soled, Adv. Catal. 39, 221(1993)

[11] R.C. Reuel and C.H. Bartholomew, J.Catal., 85, 78(1984).

[12] A.Y. Khodakov, A. Griboval-Constant, R. Bechara and V.L. Zholobenko, J. Catal. 206, 230(2002).

[13] G.L. Bezemer, J.H. Bitter, H.P. C.E. Kuipers, H. Oosterbeek, J.E. Holewijn, X. Xu, F. Kapteijn, A.J. van Dillen, K.P. de Jong, J. Am. Chem. Soc. 128, 3956(2006).

[14] E. Iglesia, S.L. Soled, and R.A. Fiato, J.Catal. 137, 212(1992).

[15] J.-S. Girardon, E. Quinet, A. Griboval-Constant, P.A. Chernavskii, L. Gengembre, A.Y. Khodakov, J. Catal. 248, 143(2007).

[16] W. Chu, P.A. Chernavskii, L. Gengembre, G.A. Pankina, P. Fongarland, A.Y. Khodakov, J. Catal. 252, 215(2007).

[17] F.P.J. Kerkhof, and J.A. Moulijn, J. Phys. Chem. 83, 1612(1979).

[18] H.P.C.E. Kuipers, Solid State Ion. 16, 15 (1985).

[19] G.A. Park, Chem. Rev. 65, 177(1965).

[20] J. van de Loosdrecht, S. Barradas, E.A. Caricato, N.G. Ngwenya, P.S. Nkwanyana, M.A.S. Rawat, B.H. Sigwebela, P.J. van Berge and J.L. Visagie, Top. Catal. 26, 121(2003).

[21] J.R.A. Sietsma, J. D. Meeldijk, J. P. den Breejen, M. VersluijsHelder, A. J. van Dillen, P. E. de Jongh, K. P. de Jong, Angew. Chem. Int. Ed. 46, 4547(2007).
[22] R.A. Sietsma, J., P. den Breejen, J., E. de Jongh, P., Jos van Dillen, A., H. Bitter, J., P. de Jong, K. Stud. Surf. Sci. and Catal. 167, 55(2007).

[23] Ø. Borg, E.A. Blekkan, S. Eri, D. Akporiaye, B. Vigerust, E. Rytter, A. Holmen, A. Top. Catal. 45 (1-4), 39(2007).

[24] J.-S. Girardon, A.S. Lermontov, L. Gengembre, P.A. Chernavskii, A. Griboval-Constant, A.Y. Khodakov, J. Catal. 230, 339(2005).

[25] J.-S. Girardon, A. Constant-Griboval, L. Gengembre, P.A. Chernavskii, A.Y. Khodakov, Catal. Today 106, 161(2005).

[26] T. Mochizuki, H. Osanai, T. Sato, D. Hongo, N. Koizumi, M. Yamada, J. Japan Institute of Energy 87 (2), 124(2008).

[27] I. Puskas, T.H. Fleisch, J.A. Kaduk, C.L. Marshall, B.L. Meyers, M.J. Castagnola, J.E. Indacochea, Appl. Catal. A 316 (2), 197(2007).

[28] P.G. Casado, I. Rasines, J. Solid State Chem. 52, 187(1984).

[29] S. Chemlal, A. Larbot, M. Persin, J. Sarrazin, M. Sghyar and M. Rafiq, Mater. Res. Bull. 35, 2515(2000).

[30] W.S. Cho and M. Kakihana, J. Alloy. Compd. 287, 87(1999).

[31] D. Schanke, S. Vada, E.A. Blekkan, A.M. Hilmen, A. Hoff and A. Holmen, J. Catal., 156, 85(1995).

[32] Y. Zhang, W. Chu, W. Cao, C. Luo, X. Wen, K. Zhou, Plasma Chem. Plasma Process. 20, 137(2000).

[33] M.H. Chen, Wei Chu, X.Y. Dai, X.W Zhang, Catal. Today 89, 201(2004).

[34] F. Guo, W. Chu, S. Z. Luo, Chin. J. Catal. 28, 429(2007).

[35] C.J. Liu, G.P. Vissokov, B.W.L. Jang, Catal. Today 72, 173(2002).

[36] W. Chu, L.-N. Wang, P. A. Chernavskii and A. Y. Khodakov, Angew. Chem. Int. Ed, 47, 5052(2008).

[37] P.A. Chernavskii, A.Y. Khodakov, G.V. Pankina, J.-S. Girardon, E. Quinet, Appl. Catal. A 306, 108(2006). 